
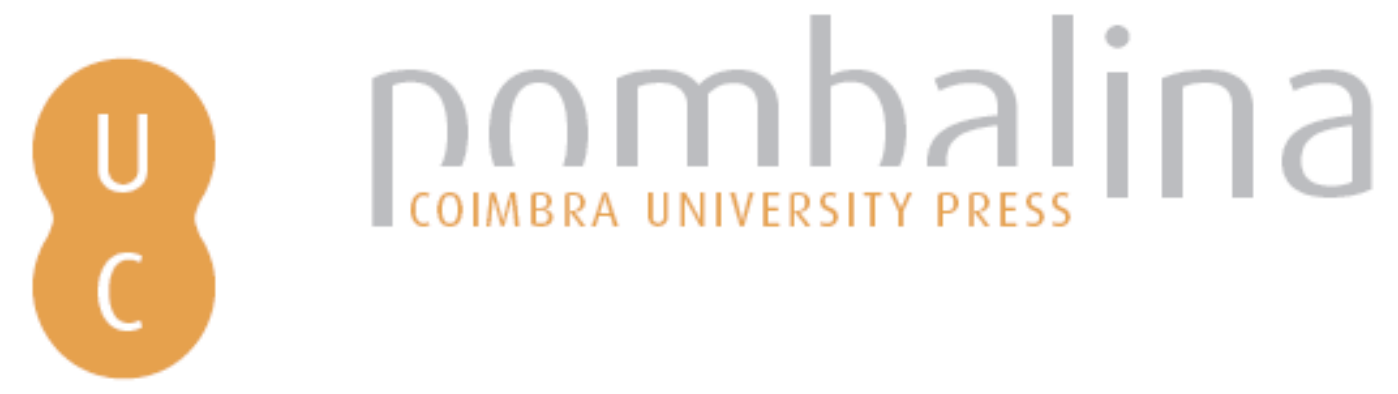

\title{
As paisagens urbanas enquanto territórios turísticos e ideológicos: o caso particular do Szoborpark, em Budapeste
}
Autor(es):
Fernandes, João Luís Jesus
Publicado por: Imprensa da Universidade de Coimbra
URL
persistente:
URI:http://hdl.handle.net/10316.2/30780
DOI:
DOI:http://dx.doi.org/10.14195/978-989-26-0244-8_22
Accessed : $\quad$ 26-Apr-2023 08:26:23

A navegação consulta e descarregamento dos títulos inseridos nas Bibliotecas Digitais UC Digitalis, UC Pombalina e UC Impactum, pressupõem a aceitação plena e sem reservas dos Termos e Condições de Uso destas Bibliotecas Digitais, disponíveis em https://digitalis.uc.pt/pt-pt/termos.

Conforme exposto nos referidos Termos e Condições de Uso, o descarregamento de títulos de acesso restrito requer uma licença válida de autorização devendo o utilizador aceder ao(s) documento(s) a partir de um endereço de IP da instituição detentora da supramencionada licença.

Ao utilizador é apenas permitido o descarregamento para uso pessoal, pelo que o emprego do(s) título(s) descarregado(s) para outro fim, designadamente comercial, carece de autorização do respetivo autor ou editor da obra.

Na medida em que todas as obras da UC Digitalis se encontram protegidas pelo Código do Direito de Autor e Direitos Conexos e demais legislação aplicável, toda a cópia, parcial ou total, deste documento, nos casos em que é legalmente admitida, deverá conter ou fazer-se acompanhar por este aviso.

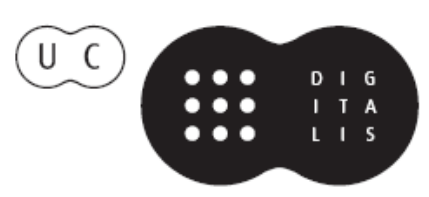




\section{TRUNFOS DE UMA}

\section{EOGRAFIA ACIVA}

\section{DESENVOLVIMENTO LOCAL,}

AMBIENTE,

ORDENAMENTO

E TECNOLOGIA

Norberto Santos

Lúcio Cunha

COORDENAÇÃO 
João Luís Jesus Fernandes

Centro de Estudos de Geografia e Ordenamento do Território (CEGOT), Departamento de Geografia, Universidade de Coimbra

\section{AS PAISAGENS URBANAS ENQUANTO TERRITÓRIOS TURÍSTICOS E IDEOLÓGICOS - O CASO PARTICULAR DO SZOBORPARK, EM BUDAPESTE ${ }^{1}$}

"(...) We cannot see landscapes as simply material features. We can also treat then as 'texts' that can be read, and which tell both the inhabitants and us stories about the people - about their beliefs and identity. These are not immutable nor ineffable; some parts may be taken-for-granted parts of everyday life, but others may be politically contested. Landscapes are open to struggles over their meanings» (CRANG, 1998, p.40).

A cidade é um espaço geográfico de múltiplas apropriações simbólicas e funcionais e a paisagem urbana a síntese da sobreposição nem sempre harmoniosa de diferentes territorialidades, de múltiplos agentes, públicos e privados, individuais e colectivos. Por isso, "a cidade não é um colectivo de vivências homogéneas" (Abreu, 1998: 86), mas um produto socioeconómico e cultural heterogéneo em constante (re)construção.

As paisagens culturais urbanas têm sido modeladas pela interacção entre o Estado e as entidades religiosas, entre estes e as apropriaçóes individuais e privadas, de grupos ou subgrupos de contra-cultura e contestação, de arquitectos, urbanistas, artistas de rua ou de publicitários, de políticos, empresários e cidadãos anónimos, que encontram na cityscape um território de expressão ideológica, manifestaçóes culturais, celebração, consumo e trabalho, de protesto, resistência e afirmação (Short e Kim, 1999; Mitchell, 2000). As cidades, pela centralidade, pelos fluxos que polarizam, pelo papel estruturador do espaço e da ordem social, têm sido privilegiadas nos processos de legitimação das elites. Nesta tensão, a cityscape foi-se construindo por registos assimétricos, proporcionais ao poder de cada actor, o que confere selectividade à memória do espaço urbano, uma memória fragmentada produzida por marcas com visibilidade e durabilidade variáveis (Abreu, 1998). Estas manifestam-se pela forma da cidade e por elementos que conferem dimensão iconográfica à paisagem urbana, como a toponímia, a estatuária ou as placas comemorativas. Para Mike Crang (1998), para além da hierarquia de poder, essa iconografia traduz o sistema de valores e os propósitos de quem os inscreveu. Este city-text é, por isso, um conjunto variável de elementos urbanos mobilizáveis para a afirmação de quem, em cada contexto histórico, domina ou pretende

\footnotetext{
${ }^{1}$ Este texto nasceu com a visita ao centro histórico de Budapeste e ao Szoborpark, localizado na periferia desta cidade. Porque levantou questôes científicas pertinentes, como a dimensão ideológica e a conflitualidade política inscritas na paisagem urbana, esta viagem estimulou, desde o primeiro contacto com o território, a análise deste estudo de caso,
} 
contestar o domínio da cidade: "The city-text functions as a system of representations and an object of political identification. (...) Structuring the everyday experience of the city and history through public commemoration, the elements of the city-text relate to the construction of political discourses and identities» (Palonen, 2008: 220).

Nesta manipulação da paisagem, tanto em regimes totalitários como em sistemas democráticos, o Estado tem tido papel de relevo, construindo territórios pedagógicos de veiculação de valores, mobilizaçáo de massas e criaçáo de narrativas comuns que filiem a comunidade a correntes políticas ou agregaçóes colectivas como o Estado-Nação. Este facto confere dimensão política à gestão da cidade - um palco de reinterpretação da História, de leitura selectiva de um passado parcial, descontínuo e manipulável, num complexo jogo de memória colectiva entre a conservação e a destruição, o convívio patrimonial com a herança ou o simples varrer do vestígio histórico que não interessa realçar, numa tensão que desafia as políticas de ordenamento do território e promove a diversidade diacrónica da paisagem (Abreu, 1998; Fernandes, 2009).

Para além de ideológicos, estes espaços patrimoniais são também territórios turísticos que mobilizam quer os símbolos de inovação quer as iconografias do passado para estratégias de marketing territorial que confiram, a cada lugar, um espírito único e o privilégio da diferenciação (Avraham e Ketter, 2008). Por isso, estas paisagens ideológicas são também actores na concorrência global pela captação de agentes em movimento, como novos residentes, investidores ou turistas (Ashworth e Larkham, 1994).

Em todos estes pontos de vista, as cidades da Europa de Leste, na antiga esfera de influência da ex-URSS, são um interessante laboratório de estudo: pelo modo como a política as apropriou e pela forma como a transição para a democracia remodelou a city-text ideológica herdada dos tempos do comunismo.

\section{AS CIDADES IDEOLÓGICAS DE INFLUÊNCIA SOVIÉTICA}

As cidades da área de influência da antiga União Soviética foram modeladas por simbologias pedagógicas de legitimação do poder político. Contudo, na Europa de Leste, náo é fácil definir o modelo geral da materialização urbana do comunismo. Primeiro, porque entre a Revolução de Outubro de 1917 e a desintegração da União Soviética, estes países acolheram regimes políticos heterogéneos e, segundo, porque apropriaram cidades diferenciadas por factores como a dimensão, a centralidade, o contexto histórico-geográfico e os níveis de industrialização e urbanização. Apesar disso, esta projecção ideológica apresentou linhas comuns, como a eliminação dos sinais da economia capitalista e a modelação da cidade à imagem do ideal da sociedade comunista em construção. Foi neste contexto que se nacionalizou e fez a gestáo centralizada da urbe, o que conferiu ao Estado plenos poderes de intervenção sobre os tecidos económicos e simbólicos desses centros urbanos, preparados para receber massas de mão-de-obra industrial mas também para promover a celebração e a legitimação ideológica do poder.

Nas city-texts de influência soviética repetem-se iconografias como a estrela do Exército Vermelho, laureado pelo papel que, durante a II Guerra Mundial, desempenhou na libertação dos territórios subjugados ao domínio alemão. Para além da valorização das praças e dos arruamentos largos e geométricos - locais de parades político-militares de afirmação do regime, como a Praça Vermelha (em Moscovo), procedeu-se à limpeza simbólica do passado, 
à renovação ideológica da toponímia e à evocação pública, através de placas, baixos-relevos ou estátuas, de personagens relevantes para a construção das sociedades comunistas, como Marx, Engels ou Lenine. Esta construção ideológica promove-se pela escala e pela verticalidade, que torna o cidadão desproporcionado em relação à generalidade dos símbolos urbanos $^{2}$. Fiel às teorias hipodérmicas da comunicaçáo de massas, a paisagem urbana seria um instrumento que manipularia receptores apáticos e modelaria uma populaçáo passiva (Katz e Lazarsfeld, 1955).

Esta modelação ideológica, com evocaçóes repetidas em vários centros urbanos, deveria criar uma rede de cidades que fosse o suporte funcional e simbólico de um território socialista supranacional, numa estratégia histórica já aplicada na expansão e consolidação de entidades políticas também assentes em redes urbanas, como o Império Romano. À escala internacional, estes espaços reproduzem as estratégias usadas para a consolidação das identidades nacionais: a re-interpretação da História; a agregação da população em torno de uma narrativa comum (neste caso, a veiculada pela Internacional Socialista); a definição de um território com forte identidade e a sua diferenciaçáo com o exterior (o mundo capitalista, entenda-se) (Crang, 1998). Com estes espaços ideológicos pretendeu-se seduzir através da utopia política, construindo uma ideascape de mensagens centralizadas e controlando as restantes esferas que, em sociedades mais permeáveis, condicionam as identidades pessoais e colectivas, como as mediascapes e a ethnoscapes (Appadurai, 2004) ${ }^{3}$. Esse condicionamento faz-se pelo controlo do espaço público que não é, nestas cidades, um território plural mas sim um espaço de manifestação do poder das elites e de domínio descendente do Estado. Com esta ideascape de propaganda também se mudaram os nomes de identificação de alguns lugares, como ocorreu com a actual Sampetersburgo, antes Petrogrado e depois, quando da implantação do regime comunista, Leninegrado (nome que se manteve entre 1924 e 1991). Para além da apropriação de territórios históricos, nesta paisagem ideológica também se criaram cidades novas, como Nowa Huta (na Polónia), construída a partir de 1949 como centro de indústria pesada mas também como um espaço de propaganda que reproduzisse as utopias do ideal comunista.

Pela sua permeabilidade, estas cityscapes são sensíveis aos momentos de ruptura e cortes abruptos que ocorreram após 1989. Este novo contexto desenvolveu outras elites, um novo nacionalismo, novos modos de gestâo da cidade e um outro city-text ${ }^{4}$. Neste contexto, como em Sampetersburgo, muitas cidades retomaram antigas denominaçóes. Assim aconteceu com Podgorica (Titograd até 1992, na ex-Jugoslávia) ou Chemnitz, na Alemanha (antes chamada Karls-Marx-Stadt) 5

\footnotetext{
${ }^{2} \mathrm{O}$ uso da verticalidade como estratégia de legitimação das elites é também comum nas paisagens urbanas de mercado (veja-se o sky-line de muitos centros urbanos) e nas paisagens religiosas (apesar dessa afirmação vertical ter, neste caso, tanto de pedagógico como de aproximação ao 'Céu Divino', como ocorreu com a construção das catedrais).

3 Para Arjun Appadurai (2004), as identidades pessoais sintetizam um conjunto de esferas de influência. Cada indivíduo fará uma construção particular de interacção entre as ideascapes, as mediascapes, as technoscapes, as finantioscapes e as ethnoscapes que traduzem influências múltiplas nas identidades pessoais, como os media, a tecnologia, o sistema económico-financeiro e os contactos interpessoais.

${ }^{4}$ No caso de Berlim, esta transição está bem representada no filme de Wolfgang Becker Adeus Lenin! (2003).

${ }^{5} \mathrm{Na}$ verdade, muitas cidades da Europa de Leste alteraram as suas denominaçôes geográficas logo depois do processo de 'Des-Estalinizaçáo' que se seguiu à morte de Estaline e ao fim do culto da personalidade deste estadista soviético. Por exemplo, na Rússia, a actual Volgograd chamou-se, entre 1925 e 1961, Stalingrad; Entre
} 
Como se verá com o exemplo de Budapeste, o fim dos regimes comunistas foi acompanhado por atitudes muito diferentes em relação ao património soviético inscrito nas paisagens urbanas - da simples remoção e destruição, à patrimonialização destes elementos simbólicos, com objectivos que oscilam entre o revisionismo histórico e a sedução de turistas.

\section{A PAISAGEM IDEOLÓGICA DE BUDAPESTE E A CRIAÇÃO DO SZOBORPARK}

Inaugurado em 1993, Szoborpark nasce porque, após 1989, se decidiu preservar os vestígios físicos da paisagem simbólica comunista e reunir esta arte pública num lugar de evocação e memória. Da autoria do arquitecto Arkos Eleod, procurou-se um projecto sóbrio - uma memoryscape de interpretação da História da Hungria e não um espaço de propaganda anti ou pró-comunista. Aqui foram colocadas 41 peças (17 estátuas e bustos, 13 placas e 11 monumentos variados de pedra ou metal), agrupadas em três conjuntos temáticos: a evocação do Exército Vermelho e dos heróis soviéticos que libertaram a Hungria da opressão nazi; a celebração de húngaros importantes no movimento operário do país; e, por fim, símbolos alegóricos da amizade entre a Hungria e a União Soviética. (Light, 2000 e James, 2005). Para além desta exposição, neste parque intertextual apresentam-se documentos e fotografias e exibem-se filmes de pedagogia ideológica, produzidos entre 1958 e 1988 com o objectivo de preparar os agentes da polícia secreta para a defesa da lei e da ordem comunista. Neste caso, o Szoborpark não proporciona uma experiência de reality tourism ${ }^{6}$ mas apenas a demonstraçáo dos métodos usados na supressão das liberdades individuais. Também neste ponto de vista estaremos perante um espaço de encenação e uma hyper-realidade (Eco, 1987).

Localizado em Tétényi (XXII Distrito), o Szoborpark insere-se na tendência geral de exportaçáo de elementos urbanos para a cintura periférica das cidades. Estas peças de arte pública não foram destruídas mas sofreram uma descaracterização simbólica quando se deslocalizaram dos centros gravitacionais da capital húngara para um espaço menos nobre, encravado em terrenos vazios, na vizinhança de casas dispersas e de rodovias periurbanas.

Para além de lembrar o passado histórico recente, o Szobopark contribui para a criação de uma narrativa comum e uma memória colectiva de coesão. A criação deste parque insere-se ainda numa corrente de patrimonialização e divulgação turística de topos de evocação comunista, em países como a Hungria, a Polónia ou a Alemanha ${ }^{7}$.

Como refere James (2005), enquanto recinto fechado na periferia da capital, Szobopark tem o simbolismo de aprisionar e confinar o comunismo num reduto longe da vida

1953 e 1956, Katowice (na Polónia) chamava-se Stalinogród; na Roménia, a actual Brasov recebeu, de 1950 a 1960, o nome de Orasul Stalin.

${ }^{6}$ Como ocorre, por exemplo, na Lituânia, onde foram recuperados abrigos subterrâneos do período soviético para que os turistas experienciem a prisão, os interrogatórios e a opressão do regime soviético.

${ }^{7}$ Refiram-se, como exemplos, Nowa Huta (na Polónia), e o campo de terror de Recsk (Hungria), até 1953 um lugar de detenção, tortura e trabalhos forçados e, desde 1996, um memorial de evocação. Em Budapeste foi criado o Museu da Casa do Terror; em Sighetul Marmatiei (na Roménia), o Museu para a Memória das Vitimas do Comunismo e da Resistência; na Alemanha, abriu o Museu Stasi e, na capital da República Checa, o Museu do Comunismo, este último associado à rota turística da Praga Socialista. 
quotidiana $^{8}$ : com este espaço metafórico, a Hungria liberta-se do domínio soviético e promove a sua viragem a Ocidente, que se concretizou, de facto, com a adesão à Nato (em 1999) e à União Europeia (em 2004).

A criação deste parque também se insere na renovação ideológica da cityscape de Budapeste após a queda do muro de Berlim, uma remodelação alvo de tensóes entre diferentes grupos políticos e níveis de poder, dos locais aos nacionais, que disputaram o controlo do espaço urbano da capital (Palonen, 2008) - "In Budapest over three hundred streets, squares, and parks were renamed. Designations such as Tractor Street, Red Army Road, and November $7^{\text {th }}$ Square were dropped, often in favor of their presocialist names honoring monarchs or saints: Hungarian-Soviet Friendship Park became Old Hill Park; Socialist Brigade Park became New Hill Park. Place names commemorating communist heroes were reinscribed with allusions to the 1956 revolution: Zoltan Schonherz Road became October 23 Road, and Elek Bolgar Square became Imre Nagy Square» (James, 2005: 22).

Foi nesse ambiente de discussão que a paisagem simbólica de Budapeste regressou à evocação de um passado suprimido no período comunista. $\mathrm{Na}$ nova capital celebra-se a grandeza da "Grande Hungria" e do Império político que dominou territórios como a Transilvânia, hoje integrada na Roménia. Em Budapeste, como noutras cidades da Europa de Leste, esta nova paisagem iconográfica ganha uma conotação nacionalista, o que se entende face a uma História recente de instabilidade das linhas de fronteira e forte mobilidade espacial da população, muitas vezes promovidas pela própria União Soviética.

Apesar da dissonância entre os diferentes partidos políticos, recuperou-se a celebração da revolta de $1956^{\circ}$, primeira tentativa de derrube do regime comunista e, de facto, o início de um ciclo de contestação e libertação que, na Europa de Leste, se completou em 1989 (Palonen, 2008).

Já em período de negociaçóes para adesão à União Europeia, sobretudo depois da vitória da direita política nas eleiçóes nacionais de 1998, voltou a dar-se centralidade à simbologia cristá, em especial a que evoca Saint István - monarca coroado no ano 1000 D.C., que terá criado a nacionalidade húngara e direccionado a Hungria para Ocidente. É neste contexto de rompimento com o passado comunista e abertura a Oeste que Budapeste confere centralidade à evocação das vítimas do Holocausto Nazi, expresso nalguns elementos simbólicos desta cidade ${ }^{10}$.

Património Mundial desde 2002, a Praça dos Heróis, que celebra o nacionalismo húngaro novecentista, é um dos elementos centrais na renovação simbólica de Budapeste. Sob a imagem do Arcanjo São Gabriel, símbolo do catolicismo romano que se difundiu nesta área, celebram-se reis e outros heróis da História húngara, como Árpad e os cavaleiros das sete tribos magiares que se fixaram na bacia dos Cárpatos um milénio antes da inauguração deste espaço monumental, em 1896.

${ }^{8} \mathrm{O}$ que contraria o propósito da city-text soviética, uma constante e persistente imposição de símbolos comunistas na vida quotidiana dos cidadãos.

${ }^{9}$ A conflitualidade em redor da celebração de 1956 ficou visível nos confrontos ocorridos na Praça Kossuth (perto do Parlamento) e noutras áreas da capital húngara, em Outubro de 2006, no dia em que se comemoravam os 50 anos dessa insurreição de trabalhadores contra a opressão comunista.

${ }^{10}$ Como, por exemplo, o renovado Museu Judaico, construído na casa de nascimento de Theodor Herzl; ou o monumento de Gyula Pauer e Can Togay, inaugurado a 16 de Abril de 2005, nas margens do Danúbio (em Peste) - sessenta pares de sapatos distribuídos por uma distância de 40 metros, que representam os judeus abatidos e lançados ao rio num episódio ocorrido durante o período nazi. 
A reconfiguração do Monumento da Libertação foi também elucidativa sobre o processo de remodelação da paisagem ideológica de Budapeste. Com 14 metros de altura e localizado no topo da colina Gellert, este monumento foi esculpido por Zsigmond Kisfaludi Strobl já no período soviético (em 1947), para comemorar a derrota do exército nazi. $\mathrm{Na}$ actualidade, mantém-se o conjunto mas, a figura do soldado soviético que existia na versão original foi removida para o Szoborpark: deste modo, celebra-se a derrota nacional-socialista mas oculta-se o contributo do Exército Vermelho para essa libertação.

Para além da componente ideológica, lugares como Szoborpark são também territórios turísticos, no geral procurados por estrangeiros mas também por locais, apesar do ressentimento que alguns sentem pela História recente, como apurou Duncan Light (2000) a propósito da patrimonialização de sítios do regime de Ceausescu, na Roménia. Szoborpark é promovido por desdobráveis distribuídos em hotéis e postos de turismo, por um site próprio e por referências em portais turísticos da cidade. Desde a sua inauguração, tem recebido uma média próxima dos 40 mil visitantes anuais, uma pequena fracção dos 2,5 milhôes que, em 2008, entraram em Budapeste (2,1 milhões dos quais foram estrangeiros) e dos 7,5 milhóes que visitaram toda a Hungria (Tourism Office of Budapeste, 2009). Repartidos entre visitantes nacionais e estrangeiros, entra-se em Szoborpark com motivaçóes e posturas muito diversificadas, do interesse cultural e de interpretaçáo histórica, ao turismo de entretenimento registado em fotografias digitais depois divulgadas em páginas pessoais na internet. Aqui acorrem húngaros para mostrar o passado aos filhos; estrangeiros que querem regressar aos tempos da cortina de ferro e ter uma visão do que se escondia por detrás do muro; aqui também afluem estudantes de Arquitectura, História e História de Arte $^{11}$. Em termos turísticos, o parque é mais um elemento da afirmação internacional de uma Budapeste promovida pelo cosmopolitismo; pela centralidade de uma cityscape imperial, sobretudo depois da atribuição, em 1987, do estatuto de Património Mundial aos centros históricos de Buda e de Peste; e pela particular relação da cidade com o Danúbio, rio com forte imagem romântica ${ }^{12}$.

\section{NOTAS FINAIS}

Este texto abordou o modo como as paisagens urbanas veiculam narrativas que procuram condicionar comportamentos, modos de pensar e valores. Contudo, estas paisagens são contestadas e resultam da tensão instável entre vários agentes, locais e extra-locais, como ocorreu depois da difusão do socialismo soviético na Europa de Leste após a revolução de 1917, que criou uma rede de cityscapes modeladas por elementos com forte visualidade que expressam concepçóes ideológicas e utópicas.

A análise deste estudo de caso abre caminho a um outro olhar sobre as cidades portuguesas, sobre a forma como estas paisagens urbanas foram disputadas e inscritas por regimes e momentos políticos como a monarquia, a implantação da república, a democratização de

\footnotetext{
${ }^{11}$ Informaçóes recolhidas no local e confirmadas por dados publicados em http://www.szoborpark.hu/ (consultado a 16 de Novembro de 2009).

${ }^{12}$ Esta imagem do Danúbio deve muito às suas representaçôes em expressóes artísticas como a música (recorda-se o célebre Danúbio Azul, de Johann Strauss filho, de 1867) e a literatura (como o livro Danúbio, de Cláudio Magris, de 1986).
} 
1974 ou a adesão europeia em 1986. Demonstrando que a apropriação ideológica da paisagem urbana não é exclusiva da Europa de Leste, também as cityscapes portuguesas foram alvo de disputas e legitimação dos poderes. Neste caso, o Estado Novo é um objecto de estudo pertinente, pelo modo como se expressou pelo desenho urbano, pela arquitectura, pela estatuária ou pela toponímia. Esta territorialização doutrinária apropriou e glorificou personagens que engrandeceriam a nacionalidade portuguesa, como o Infante D. Henrique, Vasco da Gama ou Luís Vaz de Camóes, autor de uma narrativa épica colectiva - Os Lusíadas, com forte expressão toponímica na paisagem cultural portuguesa. Com esta afirmação nacional criaram-se espaços iconográficos, como a Belém da Lisboa Imperial, onde se realizou a Exposição do Mundo Português, em 1940, mas também onde, com o Centro Cultural de Belém, se celebrou a adesão de Portugal à então Comunidade Económica Europeia (CEE). Também em Portugal se promoveram patrimonializaçôes com leituras parciais e fragmentadas da História, valorizando-se, por exemplo, em diferentes momentos, mais os espaços e as personagens da reconquista cristã que o passado de influência islâmica; mais as guerras peninsulares de restauração da nacionalidade que os territórios e as mobilidades de contacto que, ao longo do tempo, se construíram na fronteira luso-castelhana. Também neste país as concepçóes ideológicas da paisagem foram apropriadas pelo turismo, como no Portugal dos Pequenitos, um espaço de doutrina e de união simbólica do 'mundo português', uma paisagem pedagógica que une o que está distante, tornando os lugares mais familiares e o Império mais próximo, exequível e legitimado - o que foi um lugar de doutrina é agora, em democracia e num contexto pós-colonial, um espaço de lazer e um elemento da paisagem turística da cidade de Coimbra.

Szoborpark, para além de remeter para a análise de outros estudos de caso, demonstra que a cidade apropriada pelo turismo não é uma paisagem fechada e estática, mas sim um território de doutrina construído em circunstâncias de múltiplas contestaçóes culturais e político-ideológicas. Quanto ao turista, é apenas mais uma personagem de todas as que apropriam, constroem e modelam o espaço geográfico.

\section{REFERÊNCIAS BIBLIOGRÁFICAS}

Abreu, M. de A. 1998, 'Sobre a memória das cidades', Revista da Faculdade de Letras. Geografia, I Série, Vol. XIV, pp.77-97.

Appadurai, A. 2004, Dimensões culturais da globalização, Teorema, Lisboa.

Ashworth, G. J. \& Larkham, P.J (editors) 1994, Building a New Heritage. Tourism, Culture and Identity in the New Europe, Routledge, London.

Avraham, E. \& Ketter, E. 2008, Media strategies for marketing places in crisis, Butterworth-Heinemann, Elsevier, Amsterdam.

Crang, M. 1998, Cultural Geography, Routledge Contemporary Human Geography Series, Routledge, London.

Cristea, G. N. 2008, 'On Maps, Abused Virgins and Nations: Anti-Communist Memorial Museums in Hungary and Romania, NaMu (Making National Museums) IV, pp. 59-69.

Eco, U. 1987, Travels in hyper-reality, Picador, London.

Fernandes, J. L. J. 2009, 'Cityscapes - símbolos, dinâmicas e apropriações da paisagem cultural urbana', Máthesis, no 18 , pp.195-214.

James, B. A. 2005, Imagining Postcommunism. Visual Narratives of Hungary's 1956 Revolution, Texas A\&M University Press, College Station.

Katz, E. \& Lazarsfeld, P. 1955, Personal Influence, The Free Press, New York.

Light, D. 2000, 'An Unwanted Past: contemporary tourism and the heritage of communism in Romania', International Journal of Heritage Studies, Vol. 6, No. 2, pp. 145-160. 
Light, D. 2000, 'Gazing on communism: heritage tourism and post-communist identities in Germany, Hungary and Romania', Tourism Geographies, 2(2), pp. 157-176.

Light, D. et al 2002, 'Toponymy and the Communist city: Street names in Bucharest, 1948-1965', Geojournal, 56, pp. 135-144.

Mitchell, D. 2000, Cultural Geography. A critical introduction, Blackwell Publishers, Malden.

Palonen, E. 2008, 'The city-text in post-communist Budapest: street names, memorials, and the politics of commemoration', GeoJournal, no 73, pp. 219-230.

Short, J. R. \& Kim, Y.-H. 1999, Globalization and the city, Pearson/Prentice Hall, Edinburgh.

Tourism Office of Budapest 2009, Tourism in Budapest, Budapest. 